\title{
Building human capability to ensure halal supply chain compliance
}

\author{
A. Voak* \\ Deakin University, Melbourne, Australia \\ B. Fairman \\ ASEAN Institute of Applied Learning, Indonesia
}

\begin{abstract}
Halal supply chain compliance is fundamentally built on trust. A trust that all supply chain actors will ensure the hygiene, cleanliness, safety and wholesomeness of the product and the services they provide from origin to consumption. Halal supply chain compliance is not just the responsibility of regulators, certifiers and other quality assurance stakeholders. It involves a fundamental commitment to managing the product, communication and financial practices within the supply chain so that they comply with Shariah Law. With the making of this commitment come unique Human Resource Development (HRD) challenges and opportunities to ensure all supply chain actors have the skills, knowledge and attitudes to ensure that trust and respect are maintained. This paper focuses on the human capability development interventions needed to ensure Halal supply chain compliance and to assure brand claims remain consistent with the expectations of Muslim and non-Muslim consumers. The growing complexity of global supply chains, along with the interdependency of the actors involved at each stage, means that considerable effort and investment should be made on better understanding the management human actors within this process. The people component is a fundamental piece of the compliance puzzle, in not only meeting the regulatory and certification requirements of Halal but also establishing the respectful practice of all stakeholders needed to maintain trust within the system.
\end{abstract}

Keywords: human capability development, halal supply chain, halal logistics

\section{INTRODUCTION}

People fundamentally drive halal supply chains and its service quality is largely dependent on the nature of personal inputs and outputs. In a Halal supply chain, the sum of these individual activities must combine seamlessly across all business activities to ensure Sharia law compliance from origin to consumption (Omar \& Jaafar 2011). However, global trade complexity and the lengthening of food supply chains have made compliance increasingly more challenging. It has become evident that with this increase in complexity comes an urgent need for increased human resource development. This human resource development must focus on new levels of knowledge, skills, abilities, values and social assets the employee must possess which will ultimately contribute to the excellence of their performance (Hashim \& Shariff 2016) and consequently to the assurance of strict compliance. This Halal compliance extends well beyond what is considered permissible, acceptable or indeed lawful and includes standards, guidelines and processes related to hygiene, cleanliness, quality, trustworthiness and safety (Ab Talib et al. 2015; Supian et al. 2019).

Modern Halal supply chains are characterized and shaped by their interdependencies, which are tested as products move through every stage of production and between vast distribution networks towards the final consumer (Rejeb 2018). Globalization has illuminated a range of challenges and

*Corresponding author 
risks for Halal food supply chains (Kamalahmadi \& Parast 2016; Supian et al. 2019). Globalization has necessitated that food travels greater distances (Ali et al. 2017) and the longer the chain, the greater its vulnerability (Supian et al. 2019). The strength of the links between supplier efficiency, supply chain performance and customer service has now become, in a significant way, critical to the maintenance of trust and respect of services.

To ensure their long-term viability, suppliers and producers now need to improve their association with retailers and customers to ensure they meet heightened expectations. These growing customer demands mean more emphasis is being placed on efficiencies and speed to market. While efficiency and effectiveness are fundamental principles of any supply chain, suppliers must also be mindful of product quality maintenance and the trust placed in certification regimes, all of which can impact on Halal integrity (Yaacob et al. 2016). As consumers become better informed and knowledgeable, and as global food safety crises and incidents sharpen their awareness, they become more concerned with food origin, authenticity, safety and quality (Abd Kadir et al. 2016). Therefore, the human element becomes a critical piece of the puzzle, as workforces build the resultant capability needed along Halal food supply chains to respond to these market expectations.

\section{HALAL FOOD SUPPLY CHAIN COMPLIANCE}

Compliance is becoming more complex, with Halal supply chain producers and their service-related actors required to ensure transparent information flows which outline not only origin and composition but also their certification or regulatory status. Further, many organizations have embraced global sourcing to reduce costs, with this often resulting in unintended risks and unanticipated consequences. These practices have introduced further complexity by creating interdependency amongst and between supply chain actors, all of which must meet Halal requirements. To better understand these interdependencies, interrelationships and resultant compliance risks, the mapping of the Halal supply chain is crucial. Mapping Halal supply chains creates greater visibility by identifying and mitigating non-compliance and critical control points which need to be effectively monitored.

There are many hygiene, cleanliness, safety and wholesomeness requirements that should be controlled, practiced and followed to avoid disruptions to the Halal supply chain. Potential regulatory scrutiny, for example, could lead to negative impacts on the organization's bottom line and reputation. Therefore, a Halal supply chain compliance program must serve as an enabler to not only better control product quality, transparency of information and regulated financial flows, but also to increase their visibility. A compliance program is thus a vital element of a broader enterprise risk mitigation strategy. To mitigate the risk of non-compliance, suppliers must try to understand the linkages and interdependencies that exist between supply chain actors more clearly. Comprehensive enterprise Halal supply chain risk management must implement the diligent anticipation, monitoring, management and assurance of operational practices of all actors. A harmonized and integrated Halal supply chain compliance program must include appropriate risk-management activities and controls through all three major supply chain flows, those of financial, product and information flows from producer to consumer.

\section{FACETS OF COMPLIANCE AND HUMAN CAPABILITY REQUIREMENTS}

\subsection{Segregation, cross contamination, food hygiene and cleaning}

Currently, the main emphasis of Halal compliance is being placed on the assurance, regulation and certification of food production processes. These associated standards aim to control the cleanliness, hygiene and cross-contamination with non-Halal foods while in production, manufacturing, on-farm facilities and in slaughtering facilities. Physical segregation is not only critical in the production phase but also along the supply chain to preserve its Halal status (Abd Kadir et al. 2016). 
Suppliers and producers must, therefore, ensure that logistics equipment, facilities and the associated infrastructure that support distribution meets compliance requirements. This infrastructure and equipment must be consistently monitored, maintained, cleaned and the necessary mechanisms implemented to avoid contamination. To ensure complete chain compliance, suppliers must ensure that they have controlled all stages of distribution, including transparency in product movement. This transparency or visibility is vital in securing those logistics-related services which are needed to deploy preventive or mitigating measures along the supply chain.

All Halal supply chain actors must ensure appropriate hygiene maintenance is undertaken. This program should include regular vetting of cleaning, sanitation, waste and pest control systems of all logistics service providers. Established protocols must be followed, and personal hygiene of distribution staff must be monitored. These compliance regimes should also extend to adequate hygiene control measures and protocols while product is in transit. Further, Halal products must be clearly labelled and visible for identification purposes. Additionally, all workers, performing operational duties should be adequately trained in Halal food hygiene and protocols to maintain continuity and integrity of product flows (Nor et al. 2016).

\subsection{Halal provenance, fraud and traceability}

With the increase in complexity of food supply chains, consumer concerns over the provenance of Halal food that is claimed to have been prepared in accord with religious requirements, are gaining importance. Instances of improper identification and sale of Halal meat-based products, for example, have given rise to questions over the authenticity of such foods (Thomas et al. 2017). Halal food fraud appears to be on the rise since an increasing number of cases regarding the misuse of Halal Certification and Regulatory logos have been identified. These fraudulent practices indicate that there are weaknesses in unequivocally determining product compliance (Supian et al. 2019). Halal food traceability is a shared responsibility of all actors and stakeholders along the Halal supply chain (Supian et al. 2019). Halal traceability aims to identify the product, process, participant and marketing attributes and associated logistics information in the supply chain seen from an upstream as well as from a downstream perspective, and handling should be recorded at each node and stored centrally in a secure database (Khan et al. 2018).

To further facilitate traceability implementation, it is incumbent on Halal certification and regulatory bodies to introduce standardization protocols using the same accreditation standards (Hassan et al. 2016). Traceability and tracking systems are tools for rapid communication, and aim to increase the transparency of information flows within the supply chain (Zailani et al. 2010), all of which require significant collaboration among all the parties involved (Mohd Saifudin et al. 2017). It is of note that a considerable hurdle for the continued security and resultant growth of the Halal industry is the lack of agreed Halal standards that are acceptable to Muslims worldwide; it is a matter of record that each country has its own Halal compliance standards which make control and checking difficult (Majid et al. 2015).

\section{DEVELOPING HALAL SUPPLY CHAIN HUMAN CAPABILITY}

Job knowledge (the how) and Shariah knowledge (the why) are required for developing human capability along the Halal supply chain. Not only do actors along the supply chain require the job skills and knowledge relevant to their traditional operational roles, but within a Halal environment, they will also need to acquire new knowledge. This knowledge acquisition should target Halal Islamic rulings and Shariah law, awareness of Halal-Haram principles and appropriate Halal management practices (Shariff et al. 2016). To ensure Halal compliance, professional standards of practice and ethics for every key role along the chain, should be agreed upon and maintained, through widely recognized National and International professional associations (Shariff et al. 2016).

Previous research has identified critical issues regarding Halal logistics, focused on the governance of practices, these include: (i) the transportation and distribution security of food, (ii) the 
regulated storage and warehousing of perishable goods, and (iii) the manner of materials handling and operational processing at terminal nodes (Tieman et al. 2012; Tieman 2013; Talib et al. 2014; $\mathrm{Ab}$ Talib et al. 2015). To meet these Halal operational requirements, each of these facets must ensure the physical separation of Haram (non-Halal) products, even if they are inside containers or on different shelves in the cold-rooms or warehouses.

The requirements for keeping track of changes in technology and the related challenges of information management are now commonplace in supply chains. Employees must be adequately trained to allow them to access and use technology related to the transport and provenance of material under their control. It is well recognized that non-stop technological change adds to the many other human resources challenges which are related to job redesigning and the development of new skill sets. These concerns overlap with Halal training programs in that technological skills are very much needed to provide transparent Halal management. Sharia knowledge is also clearly essential if people within the supply chain are to be able to interpret food handling conditions appropriately. However, what currently makes this situation somewhat complicated, is that consistency of existing programs of instruction for personnel regarding transport duration, protection of contents and coverage of emergencies (Jamaluddin et al. 2015) are not built on a foundation of agreed occupational standards. Whilst training is deemed necessary by supply chain employers; this requires financial investment and other opportunity costs for their employees. An adequate "training needs" analysis along the supply chain needs to be conducted to ensure any human capital interventions close competency halal compliance knowledge, skills, and attitude gaps (Majid et al. 2019). Against this uncertain background, there is also a real need to develop skill sets and micro-learning opportunities to manage fast-changing technologies which will support Halal compliance.

\section{HRD OPPORTUNITIES AND HALAL LOGISTICS HUBS}

The task facing HRD professionals is a complex one since the set of requirements imposed by Halal authorities is difficult to integrate within the complex and intricate transactions common to supply chain soft and hard infrastructure. Issues of planning, collaboration, teamwork, leadership and creativity, which are part of a growing supply chain structures, must now be cast against often varying cross-border sets of compliance principles.

In this in-between period, where supply chain actors and Halal requirements are becoming more widely acknowledged, there is a need for the sharing of knowledge and techniques within the area. A possible vector here could be the use of 'Communities of Practice' where ideas and practices can be detailed and considered by a range of stakeholders. One such community of practice could involve a careful investigation of logistics hubs and transport modality integration. The notion of Halal logistics integration and coordination could potentially contribute to greater compliance and the assurance of products (Karia 2019).

Findings from a desk review of current Halal compliance practices and approaches have highlighted that logistics systems face significant challenges in keeping pace with the global growth of the sector. Further, the human actors involved in logistics-related services and activities require significantly more training, particularly around Halal awareness and the resultant operational compliance protocols. There is an urgent requirement for more reliable and standardized human resource development systems which clearly enunciate the skills, knowledge and attitudes needed by Halal logistics personnel. This integrated planning would set the scene for processes which could be reflected in agreed cross-border Halal occupational standards (Voak \& Fairman 2020). The review also revealed that greater clarity is needed around the competencies needed from producer to consumer to manage Halal supply chain compliance effectively. With these lessons in mind, more significant effort needs to be placed on raising the importance of the human element and its impact on Halal compliance. The subsequent human resource development needs for this sector will need to consider and determine how HR for Halal supply chain compliance can be strengthened particularly with a focus on the potential of Halal logistics hubs (Mahidin et al. 2016). 
Apart from the fundamentals of supply chain management, more significant cooperation between supply chain actors and other disciplines are critical in provisioning Halal food compliance and their resultant integrity. Human resource planning, management and development along the whole Halal supply chain must be comprehensively and systematically addressed to provide consumer trust. Halal supply chain compliance is only as strong as the human beings that serve the food ecosystem. For human capability development to accord with Halal compliance, it must go beyond current knowledge and skills development. Human development interventions along the chain must look closely at building the cultural competence, attitudes and values necessary to prevent fraud, preserve food integrity and the integrity of Halal regulatory and certification systems.

The above discussions illustrate some of the complexities that organizations face in designing Halal supply chain compliance programs, and the measures required to mitigate risks. Further research is needed to develop a fuller understanding of the appropriate and responsive occupational standards that may be necessary to assist organizations in responding to the growing complexities of Halal supply chain compliance. Such an investment would assist in the minimizing of disruptions and breaches that could impact on Halal brand reputation and consumer trust.

\section{REFERENCES}

Ab Talib, M. S., Hamid, A. B. A., \& Zulfakar, M. H. (2015). Halal supply chain critical success factors: a literature review. Journal of Islamic Marketing.

Abd Kadir, M. H., Rasi, R. Z. R. M., Omar, S. S., \& Manap, Z. I. A. (2016). Halal Supply Chain Management Streamlined Practices: Issues and Challenges. IOP Conference Series: Materials Science and Engineering,

Ali, M. H., Zhan, Y., Alam, S. S., Tse, Y. K., \& Tan, K. H. (2017). Food supply chain integrity: the need to go beyond certification. Industrial management \& data systems.

Hashim, H. I. C., \& Shariff, S. M. M. (2016). Halal supply chain management training: issues and challenges. Procedia Economics and Finance, 37, 33-38.

Hassan, W. A. W., Ahmad, R., Hamid, A., Megat, N., \& Zainuddin, M. (2016). The Perception on Halal Supply Chain Management Systems Implementation of SMEs in Selangor. Indian Journal of Science and Technology, 9, 34.

Karia, N. (2019). Halal logistics: practices, integration and performance of logistics service providers. Journal of Islamic Marketing.

Khan, S., Haleem, A., Khan, M. I., Abidi, M. H., \& Al-Ahmari, A. (2018). Implementing traceability systems in specific supply chain management (SCM) through critical success factors (CSFs). Sustainability, 10(1), 204.

Mahidin, N., Othman, S. N., \& Saifudin, A. M. (2016). Halal logistics issues among the food industry companies: A preliminary study. Journal of Global Business and Social Entrepreneurship (GBSE), 2(1), $34-40$.

Majid, M. A. A., Abidin, I. H. Z., Majid, H., \& Chik, C. T. (2015). Issues of halal food implementation in Malaysia. Journal of Applied Environmental and Biological Sciences, 5(6), 50-56.

Majid, Z. A., Kamarulzaman, N. H., Rahman, A., Jaafar, H. S., Rahman, N. A. A., \& Mohammad, M. F. (2019). Halal Integrity from Logistics Service Provider Perspective. Int. J Sup. Chain. Mgt, 8(5).

Mohd Saifudin, A., Othman, S. N., \& Mohamed Elias, E. (2017). Exploring in setting a model for Islamic supply chain in Malaysia. International Review of Management and Marketing, 7(1), 95-102.

Nor, M. R. M., Latif, K., Ismail, M. N., \& Nor, M. N. M. (2016). Critical success factors of halal supply chain management from the perspective of malaysian halal food manufacturers. Nigerian Chapter of Arabian Journal of Business and Management Review, 62(3804), 1-23.

Omar, E. N., \& Jaafar, H. S. (2011). Halal Supply Chain in the Food Industry: A Conceptual Framework.

IEEE Symposium on Business, Engineering and Industrial Application (ISBEIA), Langkawi, Malaysia, Rejeb, A. (2018). Halal Meat Supply Chain Traceability Based on HACCP, Blockchain and Internet of Things. Acta Technica Jaurinensis, 11(1).

Shariff, S. M., Mohamad, S., \& Hashim, H. I. C. (2016). Human Capital Development in Halal Logistics: Halal Professionals or Halal Competent Persons. Journal of Applied Environmental and Biological Sciences, 6, $1-9$. 
Supian, K., Abdullah, M., \& Ab Rashid, N. (2019). Halal Practices Integrity and Performance Relationship: Are Halal Supply Chain Trust and Commitment the Missing Links? Int. J Sup. Chain. Mgt Vol, 8(6), 1045. Thomas, A. M., White, G. R., Plant, E., \& Zhou, P. (2017). Challenges and practices in Halal meat preparation: a case study investigation of a UK slaughterhouse. Total Quality Management \& Business Excellence, $28(1-2), 12-31$.

Voak, A., \& Fairman, B. (2020). Anticipating Human Resource Development Challenges and Opportunities in 'Halal Supply Chains' and 'Halal Logistics' within ASEAN. Nusantara Halal Journal, 1(1), 1-9.

Yaacob, T. Z., Jaafar, H. S., \& Rahman, F. A. (2016). An Overview of Halal Food Product Contamination Risks During Transportation. Science International, 28(3). 